\title{
Renewable energy systems: Industrial and home best practise case studies
}

\author{
Victor Nabais ${ }^{1}$, Pedro Dinis Gaspar ${ }^{2}$ and João Matias ${ }^{2}$ \\ ${ }^{1} \mathrm{MSc}$ and PhD Student in Industrial Engineering and Management \\ ${ }^{2} \mathrm{PhD}$ and Assistant Professor \\ Electromechanical Engineering Department - Engineering Faculty \\ University of Beira Interior \\ Edifício 1 das Engenharias, Calçada do Lameiro, 6201-001 Covilhã (Portugal) \\ Phone/Fax number:+351 232618521,+351 275329759/947, e-mail: victor.nabais@sapo.pt, dinis@ubi.pt, matias@ubi.pt
}

\begin{abstract}
The use of renewable energies and energy efficiency improvement systems is sometimes constrained by the investment needed for devices and its installation. However, governments have developed policies to reduce the initial costs to end-users. The increasing number of renewable energy systems can help in the reduction of the global dependency on fossil energy sources, and simultaneously can help to ensure that the carbon dioxide emissions quota is not exceeded, aiming a reduction of the green-house effect. In this sense, this paper presents two best practise case studies. One of them is in the industrial context and other in the residence context, concerning the use of renewable energy systems and energy efficiency improvement strategies. The best practice case study in industrial context involves the renewable energy systems design in an automotive sector factory, making use of solar thermal panels and energy efficiency measures. The non-industrial case study covers the analysis of the energy efficiency improvement using a thermal energy recovery system from hot water used in daily baths or showers. The direct benefits (savings) and indirect (impacts) are analysed for both case studies.
\end{abstract}

\section{Key words}

Renewable energy, Energy efficiency, Industrial context, Non-industrial context.

\section{Introduction}

The search for new energy sources and ways to improve the energy efficiency as well its use are a constant in today's world in order to reduce global dependency on fossil energy sources. The increasing awareness of the adverse effects on the environment from the use of nonclean energy sources has increased the adherence to the use of renewable energies both in industrial and home contexts. The interest of the case studies presented in this paper is demonstrated by the direct benefits (savings) and indirect (impacts) produced in industrial contexts and not industrial, making use of renewable energy strategies.

The observation of different usage and dispersion modes of thermal energy in home, public, business and others settings allow identify situations where recovered dissipated energy can revert to installed thermal sources and improve its efficiency by pre-heating the input water.
In a home context, the main purpose of this work is the thermal energy loss in daily bath with direct water disposal is analysed. Solutions based in systems that improve energy efficiency from recovering heat from hot water baths and other purposes are described. In the industrial context, is related with the analysis of the energy efficiency improvement in an industrial mechanical production facility using renewable energies as well as the analysis of the measures applied to improve the distribution and use of energy. It makes use of solar panels and electric heating of support water tanks of showers to improve energy efficiency of workers' bath. Other applications to improve energy efficiency in industrial setting are also presented, by direct (lower power consumption and less equipments damage) and induced (better air quality in working areas, with influence on comfort, welfare, health and worker productivity) benefits. The home solutions efficiency is demonstrated by its integration in facilities (during construction or applied later) in various countries, particularly in Northern Europe. For equipment in industrial context, the solutions presented are operating in an industrial production unit of mechanical elements for automobiles, which uses high standards of resources efficient management and continuous improvement.

\section{Non-industrial applications}

In a non-industrial context, the case study is related to the thermal energy recovery from hot water used in daily baths or showers and collective baths pools. The thermal energy of heated water is recovered by heat exchangers settled on the heated water pipes to pre-heat the cold water, reducing the primary thermal energy used to keep the water temperature at the desired level. Consulting catalogues of available commercial products and contacting a European company in the sector allowed the analysis of heat exchanger systems for large spaces such as swimming pools. Large facilities (hotels, schools, hospitals, sports complex or military installations) may have obtain benefits from the use of solar thermal panels and heat exchangers to recover heat from hot water. 


\section{A. Home equipments}

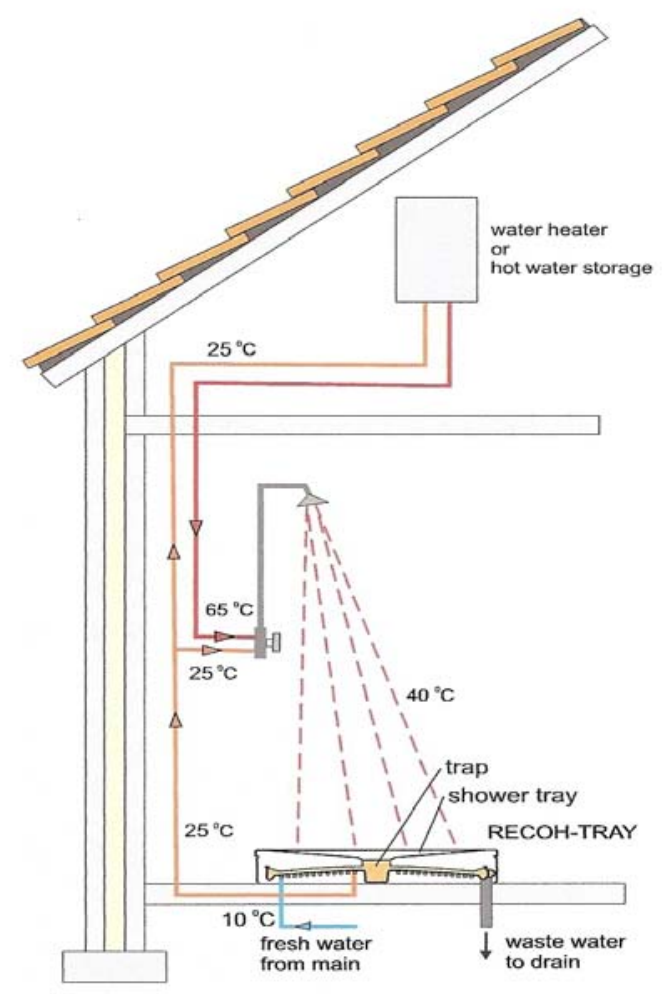

The solutions provided by a European company help to improve the energy efficiency of daily bath in private homes.

The operating procedure is as follows:

1. The primary heat source (electricity, gas) starts its operation, leading hot water to the mixer tap shower when this one is triggered;

2. The water used in bath is then sent to a heat exchanger placed beneath the shower base, which has a copper coil, where the network cold water will circulate before reaching the mixer tap and the primary heat source;

3. Absorbing a significant heat amount (the example shows that bath water at $40{ }^{\circ} \mathrm{C}$ on the recuperator, raises the temperature of network cold water from 10 to $25^{\circ} \mathrm{C}$ ), reduces the energy required for primary source to heat water bath to temperature set point $\left(65^{\circ} \mathrm{C}\right)$;

4. The availability and temperature of pre-heated water for an average shower time determines the efficiency economic of the system, which would repay its costs over a period of 4 to 5 years;

5. The equipment efficiency valued by "Kiwa Gastec Certification," reached $64 \%$ with a flow of 5.5 litre/minute and a water volume of 73 litres according to standard NEN 5128;

6 . The data in Table 1 show that the heat exchanger has an efficiency gain of $27 \%$ and a payback of 4.5 years.

Fig. 1. Home shower heat exchanger (HX) system.

Table 1 - Economic study for home shower heat exchanger system.

\begin{tabular}{|c|c|c|c|c|c|c|c|}
\hline \multirow{4}{*}{ bath } & \multicolumn{4}{|c|}{ Water } & & & \\
\hline & Volume $\left(\mathrm{dm}^{3}\right)$ & Weight (kg) & Specific heat $\left(\mathrm{J} / \mathrm{kg}^{\circ} \mathrm{C}\right)$ & Heat capacity $\left(\mathrm{kJ} /{ }^{\circ} \mathrm{C}\right)$ & & & \\
\hline & 50 & 50 & 4187 & 209 & & & \\
\hline & $\mathrm{T}_{\text {in }}\left({ }^{\circ} \mathrm{C}\right)$ & $\mathrm{T}_{\text {out }}\left({ }^{\circ} \mathrm{C}\right)$ & $\Delta \mathbf{T}\left({ }^{\circ} \mathbf{C}\right)$ & $\Delta \mathbf{E}(\mathbf{k J})$ & $\mathbf{k J} / \mathbf{k W h}$ & kWh/bath & $\epsilon / \mathbf{k W h}$ \\
\hline 1 & 10 & 65 & 55 & 11.514 & \multirow{3}{*}{3600} & 3.198 & \multirow{3}{*}{0.086} \\
\hline 2 & 25 & 65 & 40 & 8.374 & & 2.326 & \\
\hline \multirow[t]{2}{*}{$\Delta$} & 15 & 0 & -15 & -3.140 & & -0.872 & \\
\hline & €/bath & users & days & $\%$ use & $\epsilon /$ year & & \\
\hline 1 & 0.276 & \multirow{3}{*}{4} & \multirow{3}{*}{365} & \multirow{3}{*}{$80 \%$} & 323 & \multirow{2}{*}{$\begin{array}{c}\mathrm{HX} \text { invest. } \\
(€)\end{array}$} & \multirow{2}{*}{$\begin{array}{l}\text { payback } \\
\text { (years) }\end{array}$} \\
\hline 2 & 0.201 & & & & 235 & & \\
\hline$\Delta$ & -0.075 & & & & -88 & 400.00 & 4.5 \\
\hline
\end{tabular}

Legend:

1: normal bath

2: bath with heat exchanger

$\Delta$ : energy (gas) economy

\section{B. Collective equipments}

The heat exchangers efficiency increases with hot water volume and usage time duration in different tasks (showering, dishwashing, laundry), such as in hotels, restaurants, corporate cafeterias, schools, hospitals and swimming pools.
With similar operation as the system described in the previous section, the higher level of thermal energy allows for greater thermal efficiency, with gains between 40 and $60 \%$, according to data published by European companies trading this type of heat exchangers. 


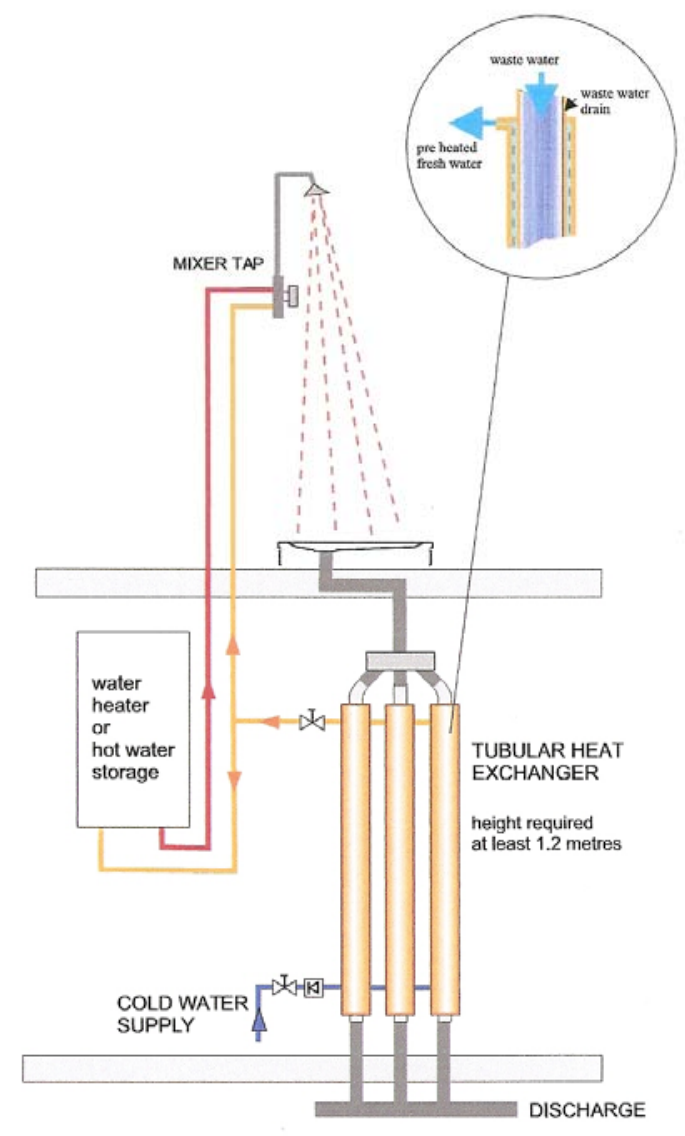

Fig. 2. Swimming pool shower heat exchanger (HX) system.

\section{Industrial applications}

The industrial application of equipments for energy efficiency improvement is usually found in large companies, where the energy costs are very high and where all the gains have an important economic dimension.

This is the case of industrial company that collaborates with this study, a multinational manufacturing enterprise of mechanical parts (engines and gearboxes) for the automotive industry.

For this study, were chosen the productive and nonproductive water heating processes as well as the air handling and air conditioning systems of industrial areas.

The best practice case study in industrial context, involves the renewable energy systems design in an automotive sector factory considering the logistics, production, working conditions, supporting services and lighting areas. The energy efficiency improvements are related with: the thermal energy sources for water heating (solar thermal cells); the hot water distribution improvement (thermal insulation of pipes and water use in closed circuit); and the replacement of large washing systems of mechanical parts by modules integrated in production processes. The solar thermal energy is used in daily baths of workers and on catering activities (meals, washing, cleaning, etc...). The manufacturing areas lighting also had efficiency improvements, making use of electronic starters and presence/activity sensors for lamps operation control.

\section{A. Productive processes}

\section{1) Fluid central}

The production efficiency and hot water supply to various plant equipment, including centralized washing of handling and transportation units of components and mechanical parts between factories, and the thermal comfort in production areas has been improved by installing a new distribution system with high thermal efficiency (closed circuit water flow and low thermal losses in duct walls) between the fluid central shown in Fig. 3 and equipment.

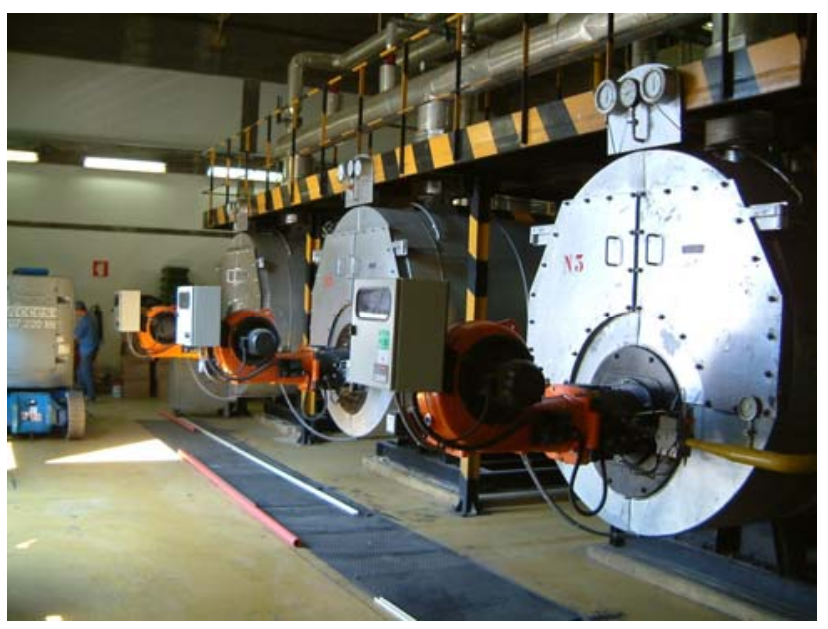

Fig. 3. Heating boiler (3).

The process requires soft water (for reuse). The choice of natural gas to replace fuel improves the equipments availability and reduces maintenance costs of boilers, pumps and ducts.

Boilers fuelled by natural gas, have a unitary capacity of 8.4 MJ being supported by four pumps with a capacity of $800 \mathrm{~m}^{3}$ of water per day.

\section{2) Washing machine (logistic units)}

The current washing high efficiency of handling and transportation units for bodies and mechanical components has been improved with new equipment (cheaper) fed by a high thermal efficiency circuit (low heat losses in ducts).

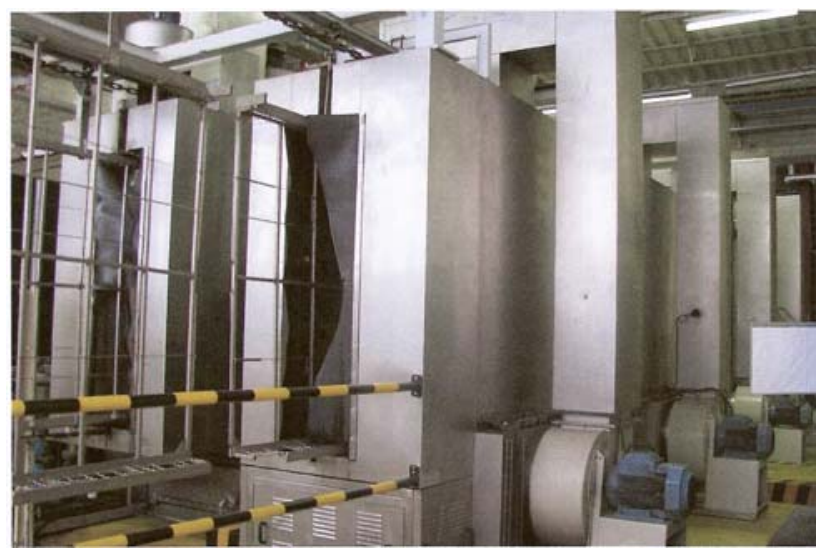

Fig. 4. Logistic units washing system. 


\section{3) Washing modules (transit components)}

The observation of thermal losses in large washing machines used in the factory led to the development of a new concept: instead of large systems that require constant technical support and full load to be used efficiently, a new solution based in small washing modules integrated in the supply chain enabling washing a piece individually, with minimum consumption of energy, water and detergent. These modules are heated by electric heaters and controlled by temperature sensors that automatically turn on and off the heating of water flow and components drying with high efficiency.

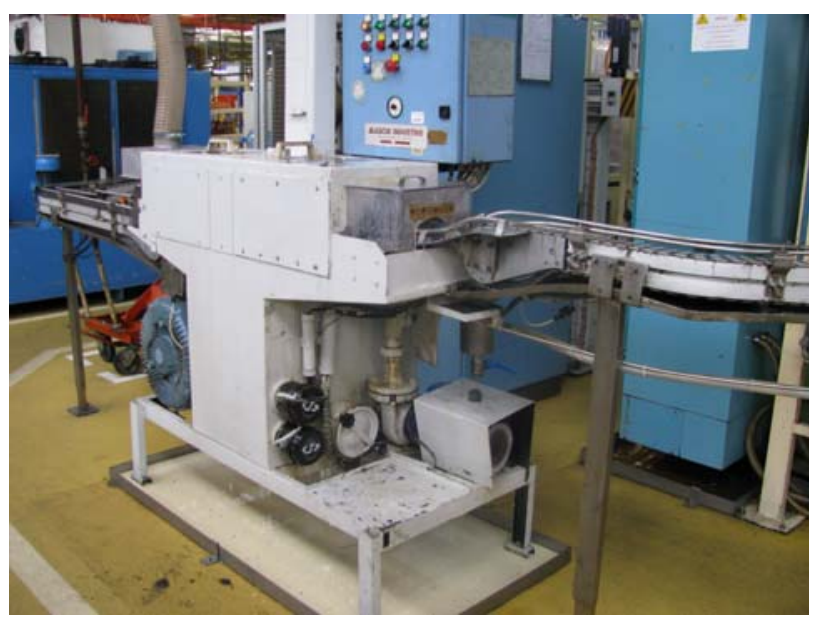

Fig. 5. Components washing module system.

The data for gains quantification obtained from technical improvements were not made available by the factory, because it is unprocessed information or from projects which main objective is improving the process and production conditions ensuring compliance of their products.

In applications to improve the working conditions listed below is included the economic study of natural gas consumption of shower baths of workers, considering the effect of solar thermal panels installation.

We note that the next industrial project in the facilities of the Enterprise considers a manufacturing facility of batteries for standard electric vehicles, with the start-up scheduled for 2012 .

\section{B. Industrial systems}

\section{1) Air handling and power recovery units}

The ambient air treatment in production site is carried out by dedicated systems, with two functions:

1. Remove, treat and renew the air inside buildings, subject to contamination by gas and oil particles, as a result of industrial activities;

To ensure a healthy atmosphere, two air handling units were installed in the gearboxes production building, with a capacity of treating $160,000 \mathrm{~m}^{3} / \mathrm{h}$ of air. A 3rd unit completes the project and will be set in the engine production building during 2012;

2. Ensure temperature suitable for cold weather, using hot water produced in the boilers described previously, which circulates in ducts thermally efficient, and whose heat is transferred to the workspace by high capacity heat exchangers (aerotherms).

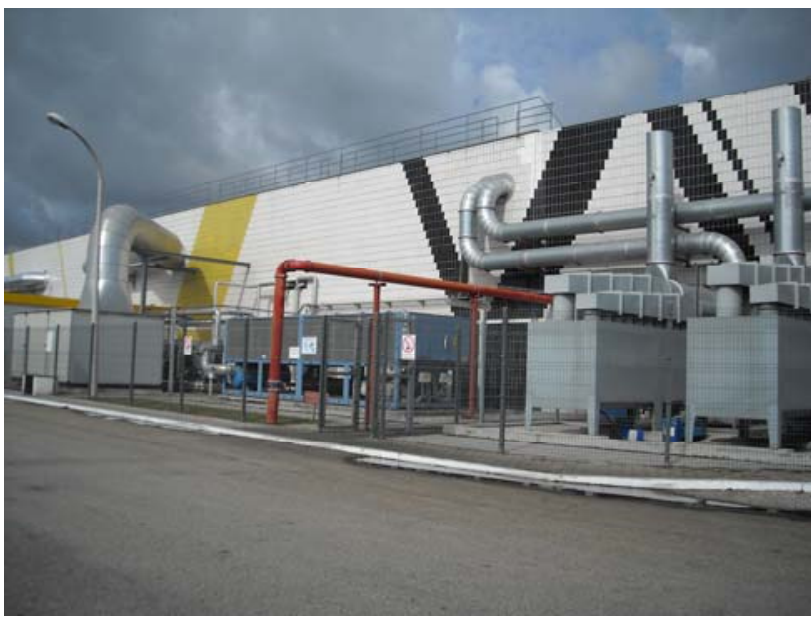

Fig. 6. Air handling unit.

The effects induced by thermal comfort (air quality and indoor temperature) in people and industrial equipment may be evaluated by the higher health level and wellbeing (less diseases), equipment availability (less damage) and physical productivity.

\section{2) Factory lighting}

Environmental quality also includes the lighting quality that, in activity daily cycles exists in workplaces, improving the tasks visualization and the probability of making quality products.

The improvement project performed at the factory included the application of electronic ballasts in all light points, with positive effect on energy consumption, reduced maintenance costs, increased visual comfort (reduced strobing effect and increased luminous flux) and additional benefits to those previously.

The physical data available are:

1) More than 3000 electronic ballasts used;

2) Total investment: $130,000 €$;

3) Direct benefits: 14,000 €/year (energy, maintenance)

4) Indirect benefits: $\quad$ Lamps lifetime: $+50 \%$

Luminous flux: $+6 \%$

\section{3) Bathrooms e Restaurant}

The energy required to heat water for daily showers of workers and for the restaurant (food preparation and dishwashing) is provided by a set of solar thermal panels installed by a reference company in renewable energy. 60 panels were installed in 2 factory buildings, with an annual capacity over than $90,000 \mathrm{kWh}$, which allows heat to $38^{\circ} \mathrm{C}$ a 9000 litres of water daily, being the additional power (during cold period) provided by electrical heaters inserted into three supply boilers, each with a capacity of 3000 litres.

The restaurant has 6 remaining panels (total of 66 solar thermal panels), with a capacity of about $9000 \mathrm{kWh} /$ year for the pre-heating of water for food preparation and several washes. 


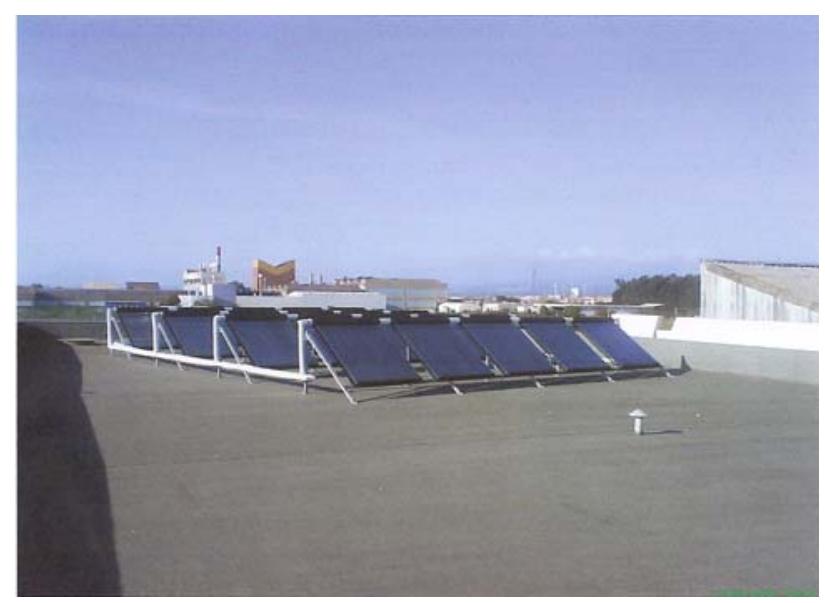

In this case, the gas consumption data throughout the year allows direct assessment of the facility economic interest, whose design lifetime of 20 years ensures profitability, environmental improvement and an interesting period of investment return as shown in Table 2.

Fig. 7. Installation of 20 solar thermal panels in the north building.

Table 2 - Energy balance of the solar thermal panels' installation.

\begin{tabular}{|c|c|c|c|c|c|c|c|}
\hline Case & $\mathrm{m}^{3}$ gas/year & $€ / \mathrm{m}^{3}$ & $€ /$ year & & & & \\
\hline 1 & 493,322 & \multirow{3}{*}{0.330} & 162,796 & & & & \\
\hline 2 & 365,544 & & 120,630 & & & & \\
\hline$\Delta \mathbf{1}$ & $-127,778$ & & $-42,167$ & & & & \\
\hline \multirow{3}{*}{ bath } & Volume (litres) & Weight (kg) & Specific heat $\left(\mathrm{J} / \mathrm{kg}^{\circ} \mathrm{C}\right)$ & Heat capacity $\left(\mathrm{kJ} /{ }^{\circ} \mathrm{C}\right)$ & & & \\
\hline & 35 & 35 & 4,187 & 147 & & & \\
\hline & $\mathrm{T}_{\text {in }}\left({ }^{\circ} \mathrm{C}\right)$ & $\mathrm{T}_{\text {out }}\left({ }^{\circ} \mathrm{C}\right)$ & $\Delta \mathrm{T}\left({ }^{\circ} \mathrm{C}\right)$ & $\Delta \mathbf{E}(\mathbf{k J})$ & $\mathbf{k J} / \mathbf{k w h}$ & kwh/bath & $€ / \mathbf{k w h}$ \\
\hline \multirow[t]{2}{*}{3} & 30 & 65 & 35 & 5,129 & 3,600 & 1.425 & 0.031 \\
\hline & €/bath & workers & work days & $\%$ use & baths/year & kwh/year & $€ /$ year \\
\hline \multirow[t]{2}{*}{$\Delta \mathbf{2}$} & 0.045 & 450 & 230 & $50 \%$ & 51,750 & 73,730 & 2,310 \\
\hline & $€ /$ year & $€ /$ year & solar panels invest. & payback & & & \\
\hline \multirow[t]{3}{*}{$\Delta \mathbf{3}$} & $-42,167$ & \multirow{2}{*}{$-39,857$} & $(€)$ & (years) & & & \\
\hline & 2,310 & & 150,000 & 3.8 & & & \\
\hline & gain & $24 \%$ & & & & & \\
\hline
\end{tabular}

Legend:

1: no solar panels (bath energy: gas)

2: solar panels (bath energy: solar)

3: solar panels (bath energy: solar+elect.)

$\Delta 1$ : energy economy (natural gas)

$\Delta 2$ : energy costs (electricity)

$\Delta 3$ : energy balance (gas + solar+electricity)

\section{Conclusion}

The installation of heat energy recovery systems in showers of private households has an undeniable interest. Although we do not pay individually $\mathrm{CO} 2$ emissions produced by the fossil fuel consumption, the return of these investments can be stimulated by tax breaks and support for purchasing equipments.

Similarly, the installation of heat exchangers in areas of medium and large size can be an important source of economy and emissions reduction.

In the home context case study, the use of heat exchangers integrated in showers, bathtubs or swimming pools allow an annual gain of $29 \%$ in gas consumption for water heating and a return of investment in 4 to 5 years, depending on the equipment cost (daily water bath, in a residence with 4 people).

The economy will also have a strong and sustained stimulus if it produces, installs and services this type of equipment, converging towards the economies of the future.

The cases presented are running in a company with good practice for continuous improvement and integration of technologies and equipment to improve the environment and energy efficiency.

In this industrial context case study, the use of solar thermal panels allows an annual gain of $26 \%$ in gas 
consumption for heating water and a return on investment of 3.6 years.

Lighting efficiency measures in the manufacturing areas, through new lighting system investments to reduce electricity consumption, not considering indirect gains (lamps longer life and higher luminous flux, less eye stress, increased productivity), ensures the return in 9 years.

Also, the economy in what concerns solar panels design, has a strong boost in the manufacture, installation and maintenance of equipments, which can be replicated in many industrial enterprises of all sizes, helping to meet the Kyoto commitments and targets of Copenhagen (with poor performance and new concerns).

Based on the proposed theme "Renewable Energy Systems", the paper was developed with examples covering energy efficiency improvement in various contexts.

In effect, improving efficiency, based on renewable energy or fossil fuels, always reduces the environmental impacts, whose consequences are already a critical issue. With all the difficulties that a current welfare model puts to initiatives to rapidly reduce the impacts from resources intensive use (energy is one example), education and training at all levels of education should be at the future forefront.

This paper reviews examples of good practice that can be applied, with multiple and major benefits.

\section{References}

[1] M. Blaauw, J. Heidemans, Recoh-tray and Recoh-vert heat exchanger, www.hei-tech.nl (2009)

[2] J.B.G. Meuleman, Efficiency of a shower water heat recovery unit, GASTEC (2007)

[3] M. Campos e F. Fernandes, Consumo de Gás Natural 2007/2008, RENAULT Cacia (2009)

[4] www.greenbusinesstech.com

Gravity Film Heat Exchanger (GFX)

[5] www.heateco.eu

Heat exchanger for wastewater 